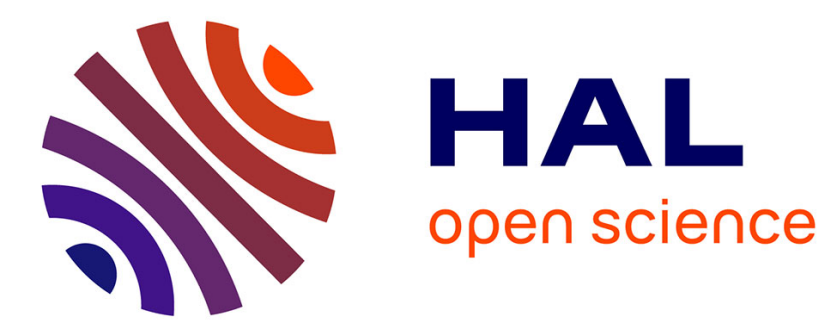

\title{
Room temperature control of spin states in a thin film of a photochromic iron(II) complex
}

Lorenzo Poggini, Magdalena Milek, Giacomo Londi, Ahmad Naïm, Giordano Poneti, Lorenzo Squillantini, Agnese Magnani, Federico Totti, Patrick Rosa, Marat Khusniyarov, et al.

\section{To cite this version:}

Lorenzo Poggini, Magdalena Milek, Giacomo Londi, Ahmad Naïm, Giordano Poneti, et al.. Room temperature control of spin states in a thin film of a photochromic iron(II) complex. Materials Horizons, 2018, 5 (3), pp.506-513. 10.1039/C7MH01042G . hal-01797021

\section{HAL Id: hal-01797021 \\ https://hal.science/hal-01797021}

Submitted on 27 Jan 2021

HAL is a multi-disciplinary open access archive for the deposit and dissemination of scientific research documents, whether they are published or not. The documents may come from teaching and research institutions in France or abroad, or from public or private research centers.
L'archive ouverte pluridisciplinaire HAL, est destinée au dépôt et à la diffusion de documents scientifiques de niveau recherche, publiés ou non, émanant des établissements d'enseignement et de recherche français ou étrangers, des laboratoires publics ou privés. 


\section{Materials Horizons}

\section{ARTICLE}

\section{Room Temperature Control of Spin States in a Thin Film of a Photochromic Iron(II) Complex}

Received 00th January 20xx, Accepted 00th January 20xx

DOI: $10.1039 / \times 0 \times x 00000 x$

www.rsc.org/
Lorenzo Poggini, ${ }^{[a, b]}$ Magdalena Milek, ${ }^{[c]}$ Giacomo Londi, ${ }^{[a]}$ Ahmad Naim, ${ }^{[b]}$ Giordano Poneti, ${ }^{[a]}$ Lorenzo Squillantini, ${ }^{[b]}$ Agnese Magnani, ${ }^{[\mathrm{d}]}$ Federico Totti, ${ }^{[\mathrm{a}]}$ Patrick Rosa, ${ }^{[\mathrm{b}]}$ Marat M. Khusniyarov, ${ }^{\text {[c] }}$ Matteo Mannini*[a]

Thin films of a molecular spin crossover iron(II) complex featuring a photochromic diarylethene-based ligand have been grown by sublimation in ultra-high vacuum on an $\mathrm{Au}(111)$ single crystal, and investigated by $\mathrm{X}$-ray and UV photoelectron spectroscopies. Temperature-dependent studies demonstrate that the thermally-induced spin crossover behaviour is preserved in thin films. The photochromic ligand deliberately integrated into the complex allows photoswitching of the spin states of this iron(II) complex at room temperature, and this photomagnetic effect is still observed in $5 \mathrm{~nm}$ thick sublimated films. Thus, this work opens new horizons and pushes bistable spin crossover systems closer to prospective applications in molecular electronics and molecular spintronics devices functioning at room temperature

demonstrated for cobalt(II/III) ${ }^{29,30}$ and nickel(II) ${ }^{31-33}$ complexes. Another approach is the optical modulation of the ligand field at the metal ion via a photoreaction at the coordinated ligand, the so called Ligand-Driven Light-Induced Spin Change (LDLISC) effect. ${ }^{34-40}$ Although the latter was proposed 24 years ago, $^{41}$ only recently ${ }^{42,43}$ photo-induced SCO at RT via LD-LISC was demonstrated for the first time to be efficient and reversible compared to previous systems. ${ }^{44,45}$ Thus, the molecular complex [Fe" $\left(\mathrm{H}_{2} \mathrm{~B}(p z)_{2}\right)_{2}$ phen $\left.{ }^{*}\right](\mathbf{1}, p z=1 \mathrm{H}$-pyrazol-1$\mathrm{yl}$, phen $^{*}=\mathrm{a}$ diarylethene-functionalized phenanthroline ligand, Figure 1), was reversibly switched between HS and LS states at RT in solution ${ }^{32}$ and in the solid state. ${ }^{43}$ The photoswitching at molecular level is driven by the reversible photocyclization of the diarylethene-based ligand leading to a systems can retain switchability even in nanostructured assemblies, including (sub)monolayers and thin films. ${ }^{3-22}$ For these reasons SCO species are thought to be highly promising candidates as active components in prospective spintronics and molecule-based data storage devices ${ }^{23-25}$ as well as in innovative devices profiting of additional features obtained by combining SCO with other functionalities. ${ }^{26,27}$ this research framework, molecular systems whose magnetic and electronic properties can be reversibly switched at room temperature (RT) are particularly attractive. ${ }^{28}$ One approach to achieve such switching is to change the coordination number of a metal complex by optical or chemical means, which was

Dr. L. Poggini, G. Londi, Prof. G. Poneti, Prof. F. Totti, Dr. M. Mannini Department of Chemistry "Ugo Schiff" and INSTM Research Unit of Firenze University of Firenze, I-50019 Sesto Fiorentino, Italy

E-mail: matteo.mannini@unifi.it

Dr. L. Poggini, A. Naim, Dr. P. Rosa CNRS, Univ. Bordeaux, ICMCB, UMR5026, F33600 Pessac, France

E-mail: lorenzo.poggini@icmcb.cnrs

M. Milek, Dr. M. M. Khusniyarov Department of Chemistry andPharmacy,

Friedrich-Alexander University Erlangen-Nürnberg (FAU), Egerlandstr. 1, 91058, Erlangen, Germany. E-mail: marat.khusniyarov@fau.de

Prof. A. Magnani University of Siena, Department of Biotechnologies, Chemistry and Pharmacy, INSTM Research Unit of Siena, Via A. Moro 2, 53100 Siena, Italy

"Present address: Institute of Chemistry, Federal University of Rio de Janeiro, Av. Athos da Silveira Ramos, no 149, 21941-909, Rio de Janeiro, Brazil

+ Electronic Supplementary Information (ESI) available: Magnetic characterization of the sublimated films; additional XPS and ToF-SIMS characterization; TDOS plot. See DOI: 10.1039/x0xx00000x

This journal is (C) The Royal Society of Chemistry 20xx

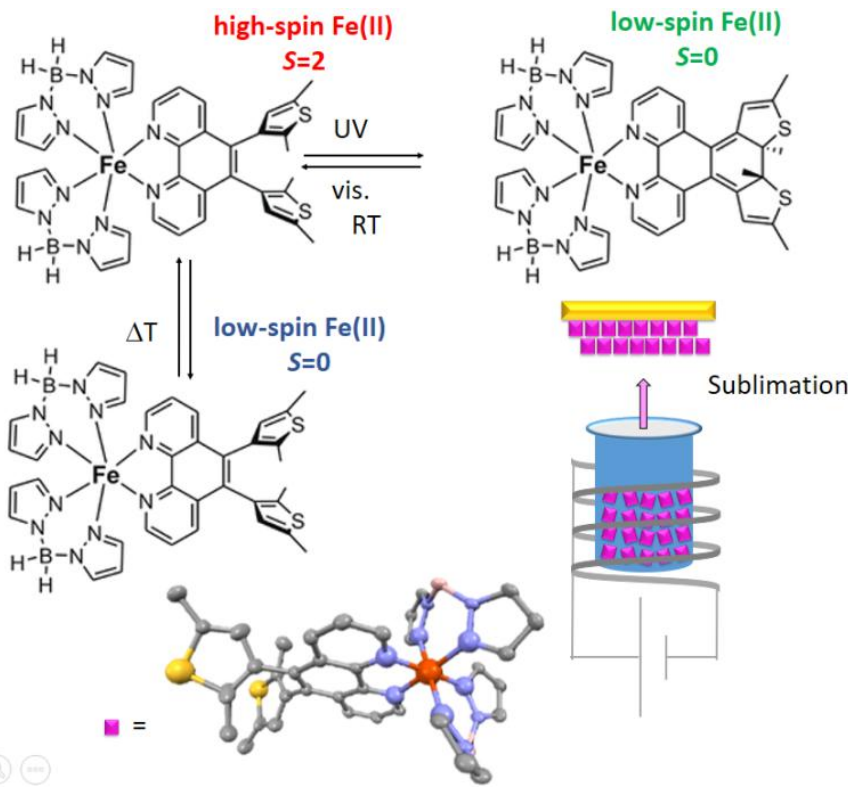

Figure 1. Molecular structure of the $\left[\mathrm{Fe}^{\prime \prime}\left(\mathrm{H}_{2} \mathrm{~B}(p z)_{2}\right)_{2} p h e{ }^{*}\right]$ complex and schematic representation of the UHV sublimation process (bottom). Control of the spin state by room-temperature photocyclization of phen* ligand and by temperature (top). 
$\mathrm{HS} \rightarrow \mathrm{LS}$ photoconversion at RT of $40 \%$ in solution and $32 \%$ in the solid state.

The incomplete photoswitching is believed to be due to the presence of two conformers of the diarylethene ligand, i.e. photoactive antiparallel and photoinactive parallel, ${ }^{46}$ present simultaneously in the studied samples. For nanostructuration purposes and prospective applications, it is highly tempting to transfer this unique iron(II) molecular photoswitch to surfaces. Indeed, some closely related SCO complexes have been reported to sublimate intact on surfaces ${ }^{47}$ and references therein.

We report herein the preparation of ultrathin films $(5 \mathrm{~nm})$ of molecular switch 1 obtained via ultra-high vacuum (UHV) sublimation on $\mathrm{Au}(111)$ substrates. A well-established protocol already used by some of us for nanosized films of other switchable magnetic molecules ${ }^{48,49}$ has been carried out for the characterization of this system at the nanoscale: this multitechnique characterization includes photoelectron spectroscopy, magnetic measurements, and mass spectrometry, in synergy with density functional theory (DFT) calculations. The results obtained have confirmed the preservation of the thermally induced SCO but have also evidenced an unprecedented light-induced SCO in thin films at RT.

\section{Results and Discussion}

A thin film of $\sim 5 \mathrm{~nm}$ corresponding to about 6-8 monolayers of 1 was grown under UHV condition by a thermal evaporation process on $\mathrm{Au}(111)$ single crystal prepared by standard sputtering and annealing cycles. The integrity of the molecular switch on the surface was preliminarily verified by time-offlight secondary ion mass spectrometry, ToF-SIMS, by comparing with a bulk reference (Figure 2). Neglecting matrix effects, similar fragmentation distributions for the bulk sample and for the thin film were observed, including, in particular, three main contributions attributable to the loss of fragments of the two $\mathrm{H}_{2} \mathrm{~B}(p z)_{2}$ ligands (a more detailed ToF-SIMS analysis

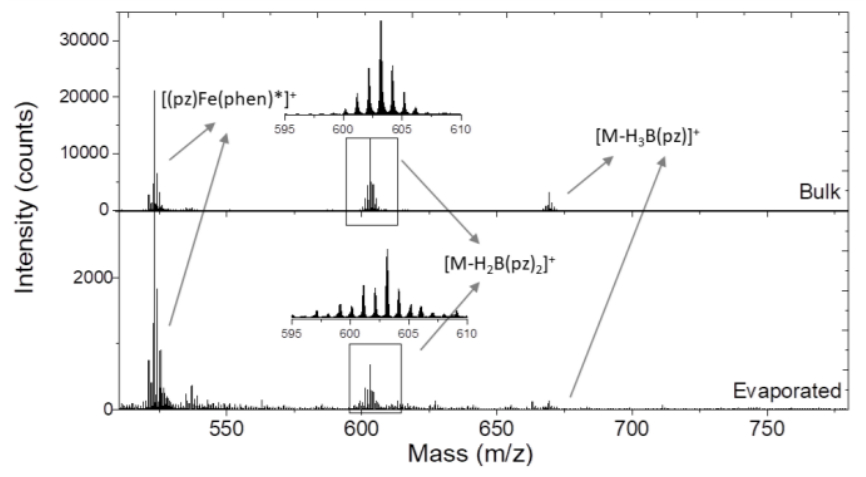

Figure 2. Comparison of the ToF-SIMS mass spectra of 1 (isotopic weight, $M=750.21$ ) in a thin film on $\mathrm{Au}(111)$ (top) and in the pristine bulk scratched on $\mathrm{Cu}$ (bottom). See Table S1 in ESI for the detailed peak description. $p z$ stands for $1 H$-pyrazol-1-yl, phen* for the diarylethene-functionalized phenanthroline ligand.

is reported in section S1). An AFM characterization has been carried out in order to confirm a nice defect-free SCO deposit excluding the presence of defective areas or Vollmer-Weber growth. The AFM estimated roughness in an area of $1.6 \mu \mathrm{m}^{2}$ resulted about $1.3 \mathrm{~nm}$ (Figure S1). Magnetic characterization of the thermally driven SCO in a thicker film $(200 \mathrm{~nm})$ on a Teflon substrate has been carried out with a SQUID magnetometer (Figure S2 in ESI). At RT, the $\chi_{M} T$ product is $\sim 2.4 \mathrm{~cm}^{3} \cdot \mathrm{K} \cdot \mathrm{mol}^{-1}$, an intermediate value between the expected ones for a pure HS-Fe" $\left(3.2-4.0 \mathrm{~cm}^{3} \cdot \mathrm{K} \cdot \mathrm{mol}^{-1}\right)$ and LS-Fe" $(\approx 0$ $\mathrm{cm}^{3} \cdot \mathrm{K} \cdot \mathrm{mol}^{-1}$ ), indicating the coexistence of HS (about 70-80 \%) and LS species (30-20\%) in the film at this temperature. On cooling, $\chi_{M} T$ monotonically decreases reaching $\sim 0.8$ $\mathrm{cm}^{3} \cdot \mathrm{K} \cdot \mathrm{mol}^{-1}$ at $50 \mathrm{~K}$ and then drops further to $0.3 \mathrm{~cm}^{3} \cdot \mathrm{K} \cdot \mathrm{mol}^{-1}$ at $2 \mathrm{~K}$ due to the zero-field splitting effect on residual HS fraction. Such behavior can be attributed to a very gradual SCO in the film with a residual HS fraction of about $25-30 \%$ remaining at low temperatures. A comparison between the thermal switching of the pristine powder sample and the sublimated film (see ESI, section S3) reveals that the nanostructuration has a strong effect on the compound, in particular inducing a much more gradual SCO transition and increasing the residual HS fraction at low temperatures (incomplete SCO). These findings can be tentatively accounted for as resulting from structural inhomogeneities and low degree of elastic interactions among interconverting molecules in the film, similarly to what previously found for doped SCO systems. $^{50,51}$

Measurements on the thick film irradiated with UV light $(\lambda=$ $282 \mathrm{~nm}$ ) evidenced the reversibility of the SCO interconversion but did not reveal significant differences in the thermal transition profile upon photocyclization of the diarylethene ligand (see Figure S3[a] in ESI). We ascribe this to very strong absorption of 1 at $282 \mathrm{~nm}$ leading to a severe penetration depth problem for a $200 \mathrm{~nm}$ film. Similar problems were identified for solid samples studied previously. ${ }^{43}$

Importantly, SCO in the thick film of $\mathbf{1}$ can be triggered at low temperature $(10 \mathrm{~K})$ also with optical stimulus: irradiation with $532 \mathrm{~nm}$ laser light increased the $\chi_{M} T$ product from 0.73 to 1.03 $\mathrm{cm}^{3} \cdot \mathrm{K} \cdot \mathrm{mol}^{-1}$ (LIESST effect), leading to the population of a metastable $\mathrm{HS} \mathrm{Fe}$ " state for about $24 \%$ in the film. ${ }^{52}$ This photoswitching can be repeated by the cyclic application of optical and thermal stimuli (see Figure S3[b] in ESI).

To further confirm the successful sublimation of $\mathbf{1}$ in UHV, we used XPS semiquantitative analysis on a $5 \mathrm{~nm}$ thin film (Table S2 in ESI). Considering the limit of the XPS technique (5\% relative error), the experimental data are in excellent agreement with the expected stoichiometry for the pristine complex. Note that sublimation in UHV was successfully used to prepare thin film and monolayer of structurally related but lighter $\mathrm{Fe}$ (II) complexes. ${ }^{5,7-11,13,14,53}$ XPS has also been used previously to follow, down to the nanoscale, the spin state evolution due to external stimuli. According to earlier literature reports, SCO in bulk ${ }^{54,55}$ and thick films ${ }^{56}$ can be monitored by using XPS at the Fe $2 p$ region.

In the present work, thermally-driven SCO has been directly observed in the thin films of $\mathbf{1}$ by studying the variation of the Fe $2 p$ peaks line shape at 300 and $150 \mathrm{~K}$ (Figure 3a). Differences in the line-shape of $\mathrm{Fe} 2 p$ recorded spectra, position of extracted components and their relative intensity (see table in 
Figure 3) point to thermally induced SCO in the film. In particular, the reversibility of the SCO transition by the temperature, becomes evident by considering the shape of the $\mathrm{Fe} 2 p_{3 / 2}$ peak centered at $710.5 \mathrm{eV}$ at RT when the HS state is dominating. Upon cooling, this peak becomes narrower, as expected for the contribution of a LS configuration, in which the coupling of the photoelectron with the partially-filled metal shell during the time of flight following ionization is occurring. ${ }^{57}$ Upon warming back to $\mathrm{RT}$, the initial line-shape is re-established and the reversibility of the transition is also confirmed by monitoring the resulting variation in the spinorbit splitting $\left(\Delta \mathrm{E}_{\mathrm{SO}}\right)$ : $13.4 \mathrm{eV}$ and $12.4 \mathrm{eV}$ at 300 and $150 \mathrm{~K}$ respectively (Figure 3 and table), well in agreement with previous reports for HS and LS components. ${ }^{10,54,56}$ Indeed, the $\Delta \mathrm{E}_{\mathrm{SO}}$ changes upon SCO due to different orbital populations in the two spin states: in the HS configuration the measured transition involves $\mathrm{e}_{\mathrm{g}}$-like type $\mathrm{d}$-orbitals that are unoccupied in the LS state.

A deconvolution analysis has been employed to follow the reversible thermally-driven SCO more carefully (Figure 3, bottom and section S4 in ESI). By monitoring the components (highlighted in green, Figure 3a) at $709.4 \mathrm{eV}$ and $721.9 \mathrm{eV}$ (A and $A^{\prime}$, respectively) univocally attributable to the LS state, ${ }^{58}$ we confirm an incomplete but reversible thermal switching. A

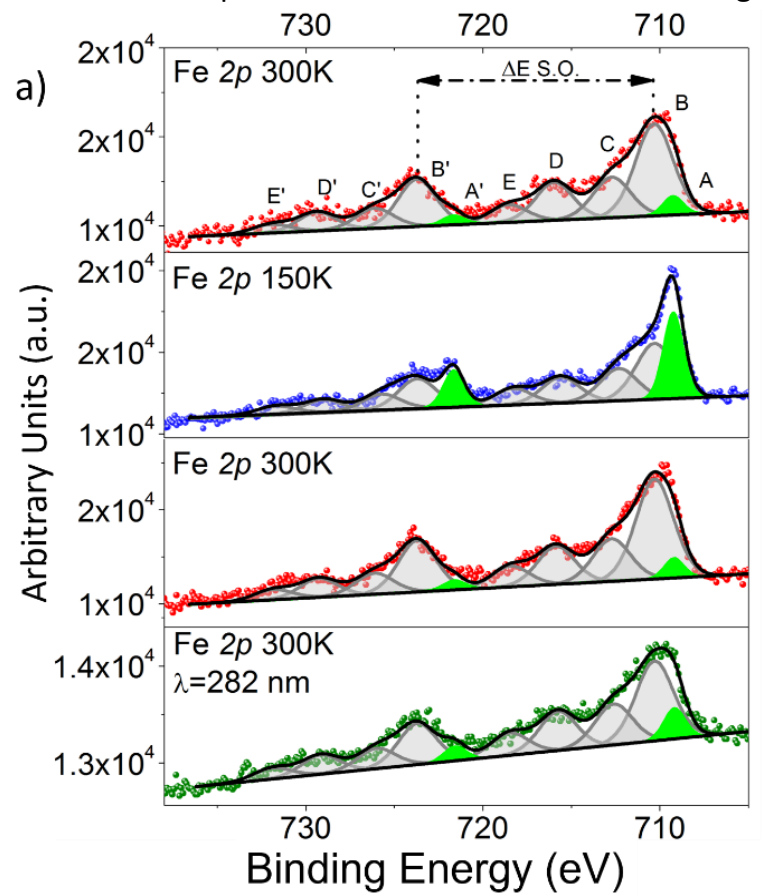

rough estimation of the conversion efficiency can be obtained by combining this fitting analysis with the $\chi_{M} T$ curve (Figure S2a): one can safely estimate that a thermal conversion of ca. $25 \pm 5 \%$ of molecules forming the film is occurring by moving from room temperature to the lowest achievable temperature accessible by the used XPS setup (about 150K). We stress that this thermally driven SCO is an entropy-driven process ${ }^{42}$ and does not involve the photo-cyclization of the phen* ligand. This can be confirmed by monitoring the $S 2 p$ region, which is identical at 300 and $150 \mathrm{~K}$ (Figure 3b). Thus the phen* ligand retains its ground open-ring configuration (phen*-o) during the thermal cycles. The S2p signal appears centered at $164.9 \mathrm{eV}$ in agreement with literature data. ${ }^{59,60}$

We investigated further the switching of the same $5 \mathrm{~nm}$ film this time via UV light irradiation at RT in an in situ XPS experiment (Figures $3 a$ and $3 b$, bottom). The film irradiated with UV light $(\lambda=282 \mathrm{~nm})$ for $8 \mathrm{~h}$ and measured at $300 \mathrm{~K}$ reveals an evolution of the $\mathrm{Fe} 2 p$ region resembling closely the changes seen during the thermally induced HS-to-LS transition. Indeed, the LS contribution, estimated using the same fitting procedure as described above, is almost doubled (8.9\%) after UV irradiation as compared to the pristine film measured at RT (5.1\%). Thus, the XPS analysis provides evidence for the photoswitching of a sublimated SCO thin film at RT.

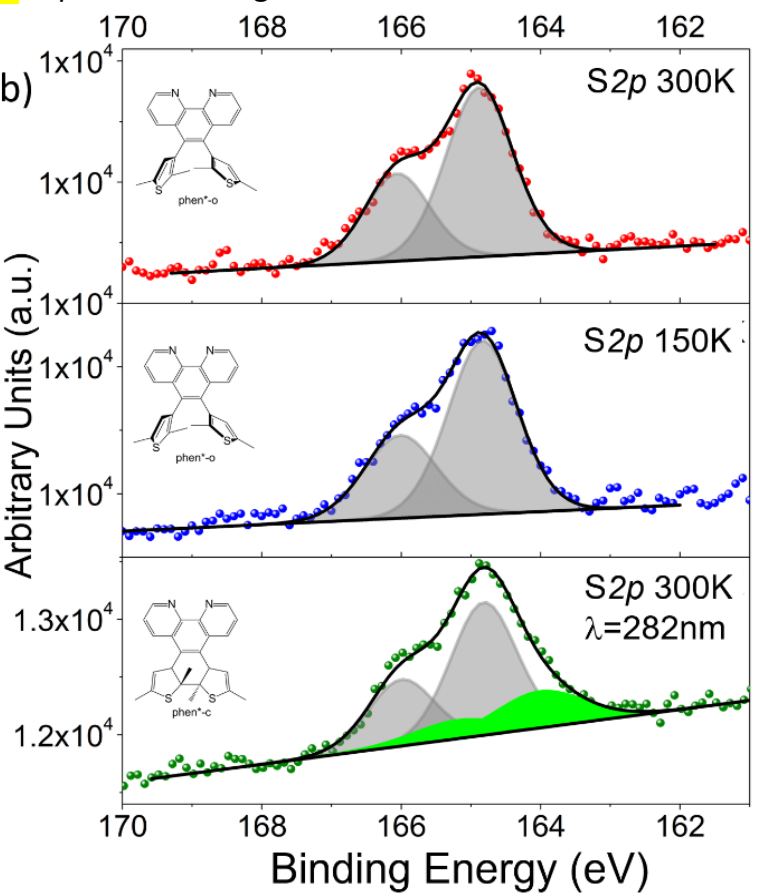

\begin{tabular}{|c|c|c|c|c|c|}
\hline Components & $A+A^{\prime}$ & $B+B^{\prime}$ & $C+C^{\prime}$ & $D+D^{\prime}$ & $E+E^{\prime}$ \\
\hline & $\begin{array}{l}\% \text {; B.E. } \\
\left(\Delta \mathrm{E}_{\text {so }}\right)\end{array}$ & $\begin{array}{l}\% \text {; B.E. } \\
\left(\Delta \mathrm{E}_{\text {so }}\right)\end{array}$ & $\begin{array}{l}\% \text {; B.E. } \\
\left(\Delta \mathrm{E}_{\text {so }}\right)\end{array}$ & $\begin{array}{l}\text { \%; B.E. } \\
\left(\Delta \mathrm{E}_{\text {so }}\right)\end{array}$ & $\begin{array}{l}\% \text {; B.E. } \\
\left(\Delta \mathrm{E}_{\text {so }}\right)\end{array}$ \\
\hline $300 \mathrm{~K}$ & $\begin{array}{c}5.10 \% ; 709.26 \mathrm{eV} \\
(12.4 \mathrm{eV})\end{array}$ & $\begin{array}{c}46.70 \% ; 710.51 \mathrm{eV} \\
(13.4 \mathrm{eV})\end{array}$ & $\begin{array}{c}20.20 \% ; 712.88 \mathrm{eV} \\
(13.4 \mathrm{eV})\end{array}$ & $\begin{array}{c}19.10 \% ; 715.94 \mathrm{eV} \\
(13.4 \mathrm{eV})\end{array}$ & $\begin{array}{c}8.9 \% ; 718.43 \mathrm{eV} \\
(13.4 \mathrm{eV})\end{array}$ \\
\hline $150 \mathrm{~K}$ & $\begin{array}{c}\text { 24.90\%; } 709.24 \mathrm{eV} \\
(12.4 \mathrm{eV})\end{array}$ & $\begin{array}{c}32.60 \% ; 710.30 \mathrm{eV} \\
(13.4)\end{array}$ & $\begin{array}{c}18.30 \% ; 712.31 \mathrm{eV} \\
(13.4)\end{array}$ & $\begin{array}{c}14.80 \% ; 715.6 \mathrm{eV} \\
(13.4)\end{array}$ & $\begin{array}{c}9.40 \% 18.30 \mathrm{eV} \\
(13.4)\end{array}$ \\
\hline $\begin{array}{l}300 \mathrm{~K}+ \\
\lambda 282 \mathrm{~nm}\end{array}$ & $\begin{array}{c}8.90 \% ; 709.18 \mathrm{eV} \\
(12.4 \mathrm{eV})\end{array}$ & $\begin{array}{c}40.20 \% ; 710.30 \mathrm{eV} \\
(13.4 \mathrm{eV})\end{array}$ & $\begin{array}{c}20.30 \% ; 712.60 \mathrm{eV} \\
(13.4 \mathrm{eV})\end{array}$ & $\begin{array}{c}19.50 \% ; 715.75 \mathrm{eV} \\
(13.4 \mathrm{eV})\end{array}$ & $\begin{array}{c}11.10 \% ; 718.40 \mathrm{eV} \\
(13.4 \mathrm{eV})\end{array}$ \\
\hline
\end{tabular}

Figure 3. Top: temperature dependence of the Fe2p a) and S2p b) peaks for a $5 \mathrm{~nm}$ film of 1 evidencing reversible thermally-induced SCO and the effect of UV irradiation at RT. Bottom: spectral components employed for least squares fitting of the Fe $2 p$ XPS Binding Energies (B.E.). Integrated areas are reported in percentages for each component. Spinorbit splitting values $\left(\Delta \mathrm{E}_{\mathrm{sO}}\right)$ are reported in brackets. 
Importantly, this unprecedented light-induced SCO is triggered remotely by the photoreaction at the phen* ligand. ${ }^{42,43}$ The UV-induced cyclization of the open-ring isomer phen*-o yields a closed-ring isomer $\left(p h e{ }^{*}-c\right)$. The increased LS fraction suggests that the latter produces a stronger ligand field at the coordinated iron(II) ion and triggers a HS-to-LS transition (LDLISC effect). In this case, being not available the magnetization data, only a rougher estimation based on the percentage of converted molecules by temperature can be obtained evidencing that about $5 \pm 1 \%$ of molecules are converting at with UV light irradiation at $300 \mathrm{~K}$.

The ligand-based photocyclization is confirmed by monitoring the $S 2 p$ region (Figure $3 b$ ). Thus, in addition to the parent component due to phen*-o at $164.9 \mathrm{eV}$ (spin-orbit coupled component at $166 \mathrm{eV})$, the UV-irradiated thin film reveals an additional component ( $25 \pm 5 \%)$ at lower binding energy (164 $\mathrm{eV}$, spin-orbit coupled component at $165.2 \mathrm{eV})$. The component at $164 \mathrm{eV}$ is in excellent agreement with the binding energy reported for a closed-ring phen ${ }^{*}-c .^{43}$ It is worth mentioning that the UV-induced converted $\mathrm{Fe}$ (II) molar fraction in the thin film is lower than the ones found for photoswitching in solution ${ }^{42}$ and in the solid state ${ }^{43}$ for the same complex. While penetration depth issues were thought to be improved with an ultrathin film, the lower efficiency found in the thin film may point towards either a smaller fraction of the photoactive antiparallel conformer of phen* or adverse packing effects in the film at the nanoscale.

A further confirmation of layer by layer growth with good roughness is given by the ultraviolet photoelectron spectroscopy (UPS) analysis carried out as a function of the thickness of the deposited molecules from $0.7 \mathrm{~nm}$ to $5.3 \mathrm{~nm}$ (ESI, Figure S5): while approaching the final thickness the almost complete attenuation of the gold valence band (VB) is clearly evident, thus excluding the presence of bare gold areas. More importantly, UPS provides additional evidences of the thermal conversion as well as of the partial photoswitching of thin films of $\mathbf{1}$ at RT. This characterization, performed on the pristine film at 300 and $150 \mathrm{~K}$ and after UV-irradiation at $300 \mathrm{~K}$ was compared with a DFT-based modelling that helped to clarify the observed effects. The UPS spectrum acquired on a 5 $\mathrm{nm}$ film at $300 \mathrm{~K}$ (Figure 4 top) evidences contributions at -2.3 $\mathrm{eV}$ (band-I), $-4.5 \mathrm{eV}$ (band-II), $-6.5 \mathrm{eV}$ (band-III), and two very broad features centered at about -9.4 and $-14.5 \mathrm{eV}$, in agreement with similar systems. ${ }^{10,14,61}$ The temperature effect on the UPS spectra is visible mainly in the valence-Fermi region (here called A region) for band-I and band-II. Indeed, upon cooling from 300 to $150 \mathrm{~K}$, we observe an increased intensity for band-I, a shift toward higher energies $(-2.3$ to $-2.2 \mathrm{eV})$ and a less intense band-II (Figure 4 middle). However, the absence of significant changes also in the semi-core (B) and core (C) regions of the spectra suggests that at $150 \mathrm{~K}$ the HS component is still present, which is in agreement with the XPS data. Upon UV light irradiation, a significant shift to lower energies $(-2.4 \mathrm{eV})$ is observed for band-I compared to the one recorded for a pristine film at $300 \mathrm{~K}$. Due to the shift to lowenergy, band-I in the irradiated sample becomes a shoulder, rather than the well separated band observed for the pristine film. We attribute this change predominantly to the photocyclization of the phen* ligand, which leads to the electronic rearrangement in the valence and Fermi regions. Indeed, similar changes were reported for the photocyclization of organic diarylethenes. ${ }^{62,63}$

The band-II is slightly affected by the cyclization giving an even slighter reduction in energy compared to $150 \mathrm{~K}$. Moreover, minor changes in the relative intensities of bands in the regions $B$ and $C$ were also observed in the UV-irradiated film. In order to clarify and to quantify the UPS results, DFT calculations on the thermo- and photoswitchable system 1 were performed. The density of states (DOS) for three species have been computed: open-ring HS complex $\left(\mathbf{1}^{\mathrm{HS}}-\mathrm{o}\right)$, open-ring LS complex $\left(\mathbf{1}^{\text {LS }}-\mathbf{o}\right)$, and the closed-ring LS complex $\left(\mathbf{1}^{\mathrm{LS}}-\mathrm{c}\right)$. For the open-ring species $\mathbf{1}^{\mathrm{HS}}-\mathbf{0}$ and $\mathbf{1}^{\text {LS }}$-o both parallel and antiparallel conformers ${ }^{37}$ were calculated but no significant differences in the DOS features have been found (Figure S4 in ESI). The computed DOS of the three species shows very similar features in regions $B$ and $C$, but differ significantly in the region $A$. Indeed, band-I becomes more intense and redshifted by passing from $\mathbf{1}^{\mathrm{HS}}-\mathrm{o}$ to $\mathbf{1}^{\mathrm{LS}}-\mathrm{c}$. Opposite trends are

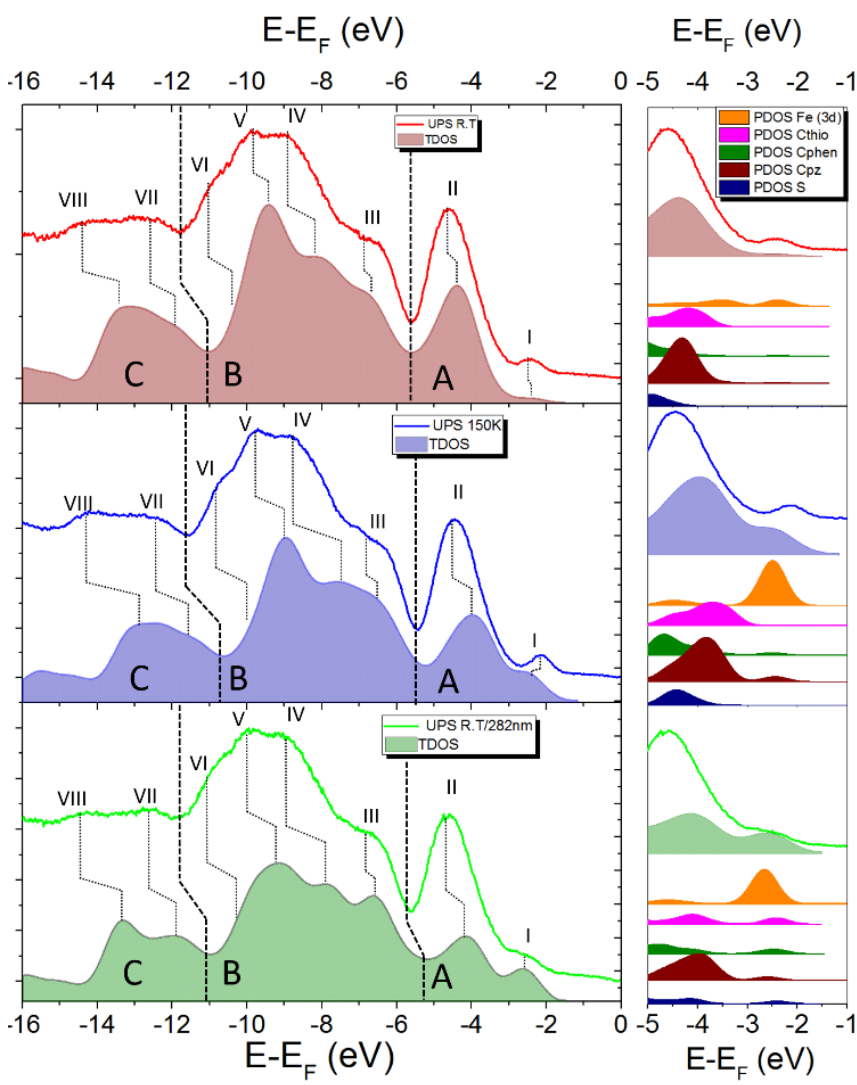

Figure 4. UPS spectra and DOS simulations. Left panel: comparison of the experimental and theoretical data in the region from $-14 \mathrm{eV}$ to $0 \mathrm{eV}\left(\mathrm{E}-\mathrm{E}_{\mathrm{F}}\right.$ ) at RT (red, top, TDOS for $\mathbf{1}^{\mathrm{HS}}$-o), $150 \mathrm{~K}$ (blue, middle, TDOS for $\mathbf{1}^{\mathrm{LS}}$-o) and after UV irradiation (green, bottom, TDOS for $\mathbf{1}^{\text {ts }}-\mathrm{c}$ ). Right panel: zoom of region $A$ of each spectrum with the calculated projected-DOS in the same conditions

computed for band-II. Therefore, Fermi and valence regions can be used as fingerprints for different species, allowing a qualitative analysis of the UPS spectra through the computed DOS features in the energy region A. Thus, the DOS calculated 
for $\mathbf{1}^{\mathrm{HS}}$-o shows a very good agreement with the spectrum obtained on a pristine film at $300 \mathrm{~K}$, supporting the major presence of the HS species at RT. The comparison of the UPS spectrum recorded at $150 \mathrm{~K}$ with the DOS computed for $\mathbf{1}^{\mathrm{HS}}$-o and $\mathbf{1}^{\mathrm{LS}}$-o supports the previous conclusion that a large fraction of HS species is still present at this temperature. In the case of $100 \%$ HS-to-LS conversion, band-II would decrease in intensity and band-I would become redshifted more significantly as observed experimentally.

DFT-based analysis of the UPS data obtained at $300 \mathrm{~K}$ after UV irradiation evidences that, although the presence of open-ring HS species is expected to be still relevant, the redshift observed for band-I and the intensity decrease of band-II are in agreement with the presence of $\mathbf{1}^{\mathbf{L S}}$-c. To shed some light on the origin of band-I and band-II, projected Density of States (pDOS) have been calculated. The resulting contributions are given in the right panel of Figure 4 . With regards to band-I, the dominant contribution of $d$-orbitals of the $\mathrm{Fe}^{\prime \prime}$ ion $(\mathrm{Fe}(3 d))$ is evident in all three considered cases. The rearrangement of $d$ electrons of $\mathrm{Fe}^{\prime \prime}$ due to the $\mathrm{HS} \rightarrow \mathrm{LS}$ transition induces an energy redshift on band-I and an increase of its intensity. On the contrary, band-II results from the convolution of several carbon atoms contributions, with the major contributions due to pyrazolyl (C-pz) and thiophenyl (C-thio) carbons. When photocyclization occurs $\left(\mathbf{1}^{\mathrm{LS}}-\mathrm{c}\right)$, minor contributions of all kind of carbon atoms including the one of the phen*-c ligand ( $C$ phen) appear in the Fermi region. Thermally-induced transition can be noticed by the blueshift of the carbon atoms contributions to band-II, while the light-induced SCO, is expected to led to a splitting of the thiophenyl carbon and sulphur (S) contributions. Overall, band-I seems to be more sensitive to the spin state of iron(II) than band-II. Therefore, band-I can be used as a "marker" to monitor both temperature-driven and light-induced SCO in iron(II) species. These effects are qualitatively observed in the reported UPS data thus confirming both the temperature induced SCO and the light-induced conversion at RT.

\section{Conclusions}

Spin-crossover molecular switch 1 featuring a photoactive diarylethene-based ligand was successfully evaporated in ultra-high vacuum to form thin films on $\mathrm{Au}(111)$. The integrity of the physisorbed complex was confirmed by mass spectrometry, XPS and DFT-supported UPS experiments. Besides thermally induced reversible switching, an unprecedented light-induced spin crossover at room temperature was achieved in thin films. This unique photoswitching is due to the photocyclization of the diarylethene-based ligand, which triggers spin crossover of the coordinated iron(II) ion remotely. Thus, this work opens new horizons for controlling magnetic properties of materials at the nanoscale down to the molecular level at room temperature.

\section{Experimental Section}

Experimental Details. 1 has been synthetized following the procedure described elsewhere. ${ }^{42}$ The molecular deposit was prepared under UHV conditions by sublimation on an $\mathrm{Au}(111)$ substrate, freshly prepared using a standard procedure involving a sputtering and annealing procedure, and then maintaining a pressure of $1 \times 10^{-10}$ mbar during the thermal sublimation of the complex. The sublimation of 1 was carried out at $425 \mathrm{~K}$ using a home-built quartz Knudsen cell and the nominal thickness was estimated using a quartz crystal microbalance (QCM). In parallel, as reference, bulk samples characterizations have been obtained by scratching the pristine powder on a Cu foil.

Direct current magnetic investigations were performed using a Quantum Design MPMS instrument equipped with a 5 T magnet. The temperature dependence of the magnetization $\left(M_{M}\right)$ was followed from 1.8 to $300 \mathrm{~K}$ by applying a $5 \mathrm{~T}$ field from 300 to $45 \mathrm{~K}$ and a $0.5 \mathrm{~T}$ field below $45 \mathrm{~K}$ to reduce magnetic saturation effects. Magnetic susceptibility per mole $\left(\chi_{M}\right)$ was then evaluated as $\chi_{M}=M_{M} / B$. Magnetic data were corrected for the sample holder contribution and for the sample diamagnetism using Pascal's constants. ${ }^{64}$

ToF-SIMS analysis was carried out with a TRIFT III time-of-flight secondary ion mass spectrometer (Physical Electronics, Chanhassen, MN, USA) equipped with a gold liquid-metal primary ion source. Positive ion spectra were acquired with a pulsed, bunched $22 \mathrm{keV} \mathrm{Au}^{+}$primary ion beam, by rastering the ion beam over a $100 \mu \mathrm{m} \times 100 \mu \mathrm{m}$ sample area. The primary ion dose was kept below 1011 ions $/ \mathrm{cm}^{2}$ to maintain static SIMS conditions. All the mass spectra were calibrated to $\mathrm{CH}_{3}{ }^{+}$(m/z 15.023), $\mathrm{C}_{2} \mathrm{H}_{3}{ }^{+}$(m/z 27.023), $\mathrm{C}_{3} \mathrm{H}_{5}{ }^{+}$( $\left.\mathrm{m} / \mathrm{z} 41.039\right)$.

Core-level XPS spectra were acquired with monochromatic $\mathrm{Al}$ $\mathrm{K}_{\alpha}$ radiation $(h v=1486.7 \mathrm{eV})$ and a SPECS Phoibos 150 electron analyzer. $40 \mathrm{eV}$ pass energy was used to ensure proper resolution and reliable semi-quantitative analysis. Spectra were taken in normal emission with the X-ray source mounted at an angle of $54.74^{\circ}$ with respect to the analyzer. The binding energy scale was calibrated by locating the substrate Au $4 f_{7 / 2}$ peak at $84.0 \mathrm{eV}$. UPS spectra were measured using the He II line $(40.8 \mathrm{eV})$ from a non-monochromatized gas discharge lamp and the same analyzer used for XPS, yielding an energy resolution of $0.18 \mathrm{eV}$. A fixed bias of $-30 \mathrm{~V}$ was applied to the sample to ensure that all the photoelectrons were detected. The spectra were taken in normal emission, and they were energy calibrated using the Au Fermi level.

The variable temperature experiment was performed by using a liquid nitrogen-based cryostat connected to the XPS sample holder. Every spectrum represented herein results from averaging 4 spectra collected after one hour of thermalisation at a specific temperature. The stoichiometry was calculated by peak integration, using theoretically estimated cross-section for each transition. ${ }^{65}$ The semiquantitative analysis has been estimated by areas of the deconvoluted peaks. The components were estimated using a fit procedure involving Gaussian-Lorentzian line-shapes, the background in the spectra was subtracted by means of a linear function. UV irradiation of the film was performed in situ using a deuterium lamp (20 W) equipped with a bandpass filter $(282 \pm 5 \mathrm{~nm})$.

Calculation details. All calculations were performed with the CP2K program package ${ }^{66}$ within the DFT framework. ${ }^{67-69}$ 
Nonlocal functional was added in order to account for the long-range dispersion van der Waals interactions. DZVPMOLOPT (double- $\zeta$ polarized molecularly optimized) basis sets were chosen for all the atomic species along with normconserving Goedecker-Teter-Hutter (GTH) pseudopotentials. ${ }^{70}$ Since no crystallographic data are available for adsorbed $\mathbf{1}$, isolated geometry of $\mathbf{1}^{\mathrm{HS}}-\mathbf{0}, \mathbf{1}^{\mathrm{LS}}$-o, and $\mathbf{1}^{\mathrm{LS}}$-c were used inside a fully periodic simulation cubic cell of $20 \AA$ A per side. A large energy cut-off of 550 Ry was applied to the plane-wave basis set. The geometry of $\mathbf{1}^{\mathrm{LS}}$-c was obtained by imposing the cyclization of the structure forcing the initial geometry.

The geometry optimizations were performed using the GGA revPBE ${ }^{71}$ energy functional with the BFGS algorithm and a convergence accuracy on nuclear forces of $4.5 \times 10^{-4}$ Hartree Bohr $^{-1}$. A convergence threshold criterion on the maximum gradient of the wavefunction in the SCF procedure of $3 \times 10^{-6}$ Hartree was used applying a Fermi-Dirac distribution with a broadening (electronic temperature) of $3000 \mathrm{~K}$. The density of states (DOS) for the three states of $\mathbf{1}$ were computed on the revPBE optimized structures by performing single point calculations using a "revised" B3LYP functional, ${ }^{67,68}$ which includes an amount of $15 \%$ of the Hartree-Fock exchange, instead of the ordinary $20 \%$. The choice of reducing the Hartree-Fock exchange amount was made accordingly to previous works. ${ }^{72}$ The computed DOS were convoluted with Gaussian functions with a full width half-maximum (FWHM, $\sigma$ ) of $0.6 \mathrm{eV}$, while all the projected density of states (PDOS) were convoluted with a $\sigma$ of $0.35 \mathrm{eV}$ for a better distinction of different atomic contributions.

\section{Acknowledgements}

We acknowledge the financial contribution of the Ente Cassa di Risparmio di Firenze for the support of the CeTeCS activities. MMK thanks the Deutsche Forschungsgemeinschaft (DFG grant 279-3/1) and the Fonds der Chemischen Industrie ( $\mathrm{FCl}$, Liebig Fellowship) for financial support, and Prof. Karsten Meyer (FAU Erlangen-Nürnberg) for his general support. PR and AN acknowledge the financial support of ANR-CHIROTS $\left(\mathrm{n}^{\circ}\right.$ ANR-11-JS07-013-01), CNRS, Université de Bordeaux and Région Nouvelle Aquitaine.

\section{References}

1 P. Gütlich and H. A. Goodwin, Spin Crossover in Transition Metal Compounds I-III, Springer-Verlag, Berlin/Heidelberg, 2004, vol. 233-235.

2 M. A. Halcrow, Spin-Crossover Materials: Properties and Applications, John Wiley \& Sons Ltd, Oxford, UK, 2013.

3 M. Gruber, T. Miyamachi, V. Davesne, M. Bowen, S. Boukari, W. Wulfhekel, M. Alouani and E. Beaurepaire, J. Chem. Phys., 2017, 146, 92312.

4 W. Kuch and M. Bernien, J. Phys. Condens. Matter, 2017, 29.

5 T. Palamarciuc, J. C. Oberg, F. El Hallak, C. F. Hirjibehedin, M. Serri, S. Heutz, J.-F. Létard and P. Rosa, J. Mater. Chem., 2012, 22, 9690. T. Miyamachi, M. Gruber, V. Davesne, M. Bowen, S. Boukari, L. Joly, F. Scheurer, G. Rogez, T. K. Yamada, P. Ohresser, E. Beaurepaire and W. Wulfhekel, Nat. Commun., 2012, 3, 938. T. G. Gopakumar, F. Matino, H. Naggert, A. Bannwarth, F. Tuczek and R. Berndt, Angew. Chemie - Int. Ed., 2012, 51, 6262-6266.
8

9
M. Bernien, D. Wiedemann, C. F. Hermanns, A. Krüger, D. Rolf, W. Kroener, P. Müller, A. Grohmann and W. Kuch, J. Phys. Chem. Lett., 2012, 3, 3431-3434.

\section{0}

A. Pronschinske, Y. Chen, G. F. Lewis, D. A. Shultz, A. Calzolari, M.

B. Nardelli and D. B. Dougherty, Nano Lett., 2013, 13, 1429-34.

A. Pronschinske, R. C. Bruce, G. Lewis, Y. Chen, A. Calzolari, M. Buongiorno-Nardelli, D. A. Shultz, W. You and D. B. Dougherty, Chem. Commun., 2013, 49, 10446.

T. G. Gopakumar, M. Bernien, H. Naggert, F. Matino, C. F. Hermanns, A. Bannwarth, S. Mühlenberend, A. Krüger, D. Krüger, F. Nickel, W. Walter, R. Berndt, W. Kuch and F. Tuczek, Chem. - A Eur. J., 2013, 19, 15702-15709.

B. Warner, J. C. Oberg, T. G. Gill, F. El Hallak, C. F. Hirjibehedin, M. Serri, S. Heutz, M. A. Arrio, P. Sainctavit, M. Mannini, G. Poneti, R. Sessoli and P. Rosa, J. Phys. Chem. Lett., 2013, 4, 1546-1552. X. Zhang, T. Palamarciuc, J.-F. Létard, P. Rosa, E. V. Lozada, F. Torres, L. G. Rosa, B. Doudin and P. A. Dowben, Chem. Commun., 2014, 50, 2255.

E. Ludwig, H. Naggert, M. Kalläne, S. Rohlf, E. Krçger, A. Bannwarth, A. Quer, K. Rossnagel, E. Kröger, L. Kipp and F. Tuczek, Angew. Chem. Int. Ed. Engl., 2014, 53, 3019-23.

M. Gruber, V. Davesne, M. Bowen, S. Boukari, E. Beaurepaire, W. Wulfhekel and T. Miyamachi, Phys. Rev. B, 2014, 89, 195415.

V. Davesne, M. Gruber, M. Studniarek, W. H. Doh, S. Zafeiratos, L. Joly, F. Sirotti, M. G. Silly, A. B. Gaspar, J. A. Real, G. Schmerber, M. Bowen, W. Weber, S. Boukari, V. Da Costa, J. Arabski, W. Wulfhekel and E. Beaurepaire, J. Chem. Phys., 2015, 142.

K. Bairagi, O. Iasco, A. Bellec, A. Kartsev, D. Li, J. Lagoute, C. Chacon, Y. Girard, S. Rousset, F. Miserque, Y. J. Dappe, A. Smogunov, C. Barreteau, M.-L. Boillot, T. Mallah and V. Repain, Nat. Commun., 2016, 7, 12212.

V. Shalabaeva, S. Rat, M. D. Manrique-Juarez, A.-C. Bas, L. Vendier, L. Salmon, G. Molnár and A. Bousseksou, J. Mater. Chem. C, 2017, 5, 4419-4425.

T. Jasper-Tönnies, M. Gruber, S. Karan, H. Jacob, F. Tuczek and R. Berndt, J. Phys. Chem. Lett., 2017, 8, 1569-1573.

20 S. Ossinger, H. Naggert, L. Kipgen, T. Jasper-Toennies, A. Rai, J. Rudnik, F. Nickel, L. M. Arruda, M. Bernien, W. Kuch, R. Berndt and F. Tuczek, J. Phys. Chem. C, 2017, 121, 1210-1219.

V. Shalabaeva, K. Ridier, S. Rat, M. D. Manrique-Juarez, L. Salmon, I. Séguy, A. Rotaru, G. Molnár and A. Bousseksou, Appl. Phys. Lett., 2018, 112, 13301.

K. Bairagi, A. Bellec, C. Fourmental, O. Iasco, J. Lagoute, C. Chacon, Y. Girard, S. Rousset, F. Choueikani, E. Otero, P. Ohresser, P. Sainctavit, M.-L. Boillot, T. Mallah and V. Repain, J. Phys. Chem. C, 2018, 122, 727-731.

E. Ruiz, Phys. Chem. Chem. Phys., 2014, 16, 14-22.

J. S. Moodera, B. Koopmans and P. M. Oppeneer, MRS Bull., 2014, 39, 578-581.

C. Lefter, V. Davesne, L. Salmon, G. Molnár, P. Demont, A. Rotaru and A. Bousseksou, Magnetochemistry, 2016, 2, 18.

J. Wang, Q. Liu, Y.-S. Meng, X. Liu, H. Zheng, Q. Shi, C. Duan and T. Liu, Chem. Sci., 2018, 0, 1-6.

K. Senthil Kumar and M. Ruben, Coord. Chem. Rev., 2017, 346, 176-205.

M. M. Khusniyarov, Chem. - A Eur. J., 2016, 22, 15178-15191. 
A. Witt, F. W. Heinemann, S. Sproules and M. M. Khusniyarov, Chem. - A Eur. J., 2014, 2, 11149-11162. A. Witt, F. W. Heinemann and M. M. Khusniyarov, Chem. Sci., 2015, 6, 4599-4609.

31 S. Venkataramani, Science, 2011, 445, 445-448.

32 M. Dommaschk, M. Peters, F. Gutzeit, C. Schütt, C. Näther, F. D. Sönnichsen, S. Tiwari, C. Riedel, S. Boretius and R. Herges, J. Am. Chem. Soc., 2015, 137, 7552-7555. G. Heitmann, C. Schütt, J. Gröbner, L. Huber and R. Herges, Dalt. Trans., 2016, 45, 11407-11412.

34 M.-L. Boillot, J. Zarembowitch and A. Sour, in Spin Crossover in Transition Metal Compounds II, ed. P. G. and H. A. Goodwin, Springer-Verlag Berlin Heidelberg, New York, 2004, pp. 261-276. M.-L. Boillot, C. Roux, J.-P. Audière, A. Dausse and J. Zarembowitch, Inorg. Chem., 1996, 35, 3975-3980. M. Nihei, Y. Suzuki, N. Kimura, Y. Kera and H. Oshio, Chem. - A Eur. J., 2013, 19, 6946-6949.

37 A. Bannwarth, S. O. Schmidt, G. Peters, F. D. Sönnichsen, W. Thimm, R. Herges and F. Tuczek, Eur. J. Inorg. Chem., 2012, 27762783.

38 K. Sénéchal-David, N. Zaman, M. Walko, E. Halza, E. Rivière, R. Guillot, B. L. Feringa and M.-L. Boillot, Dalton Trans., 2008, 19321936. M. Lawson Daku, J. Phys. Chem. C, 2010, 114, 21715-21722. Y. Garcia, V. Ksenofontov, R. Lapouyade, A. D. Naik, F. Robert and P. Gütlich, Opt. Mater. (Amst)., 2011, 33, 942-948.

J. Zarembowitch, C. Roux, M.-L. Boillot, R. Claude, J.-P. Itie, A. Polian and M. Bolte, Mol. Cryst. Liq. Cryst. Sci. Technol. Sect. A. Mol. Cryst. Liq. Cryst., 1993, 234, 247-254. M. Milek, F. F. W. Heinemann and M. M. M. Khusniyarov, Inorg. Chem., 2013, 52, 11585-92.

B. Rösner, M. Milek, A. Witt, B. Gobaut, P. Torelli, R. H. Fink and M. M. Khusniyarov, Angew. Chemie Int. Ed., 2015, 54, 12976-12980. Nishibori and H. Nishihara, Inorg. Chem., 2012, 51, 5188-5198. Y. Hasegawa, S. Kume and H. Nishihara, Dalton Trans., 2009, 2, 280-284.

M. Irie, T. Fukaminato, K. Matsuda and S. Kobatake, Chem. Rev. 2014, 114, 12174-12277.

47 H. Naggert, J. Rudnik, L. Kipgen, M. Bernien, F. Nickel, L. M. Arruda, W. Kuch, C. Näther and F. Tuczek, J. Mater. Chem. C, 2015 3, 7870-7877

G. Poneti, L. Poggini, M. Mannini, B. Cortigiani, L. Sorace, E. Otero, P. Sainctavit, A. Magnani, R. Sessoli and A. Dei, Chem. Sci., 2015, 6 2268-2274.

G. Poneti, M. Mannini, B. Cortigiani, L. Poggini, L. Sorace, E. Otero, P. Sainctavit, R. Sessoli and A. Dei, Inorg. Chem., 2013, 52, 11798805.

G. Félix, W. Nicolazzi, M. Mikolasek, G. Molnár and A. Bousseksou, Phys. Chem. Chem. Phys., 2014, 16, 7358. M. Nishino, K. Boukheddaden, Y. Konishi and S. Miyashita, Phys. Rev. Lett., 2007, 98, 1-4.

52 A. Hauser, Top. Curr. Chem., 2004, 234, 155-198. Serri, S. Heutz, M.-A. Arrio, P. Sainctavit, M. Mannini, G. Poneti, R. Sessoli and P. Rosa, J. Phys. Chem. Lett., 2013, 4, 1546-1552.

K. Burger, C. Furlani and G. Mattogno, J. Electron Spectros. Relat. Phenomena, 1980, 21, 249-256.

M. S. Lazarus, M. A. Hoselton and T. S. Chou, Inorg. Chem., 1977 16, 2549-2553.

E. C. Ellingsworth, B. Turner and G. Szulczewski, RSC Adv., 2013, 3, 3745.

Y. G. Borod'ko, S. I. Vetchinkin, S. L. Zimont, I. N. Ivleva and Y. M. Shul'ga, Chem. Phys. Lett., 1976, 42, 264-267. L. Y. Johansson, R. Larsson, J. Blomquist, C. Cederström, S. Grapengiesser, U. Helgeson, L. C. Moberg and M. Sundbom, Chem. Phys. Lett., 1974, 24, 508-513.

J. Chastain and J. Moulder, Handbook of $x$-ray photoelectron spectroscopy: a reference book of standard spectra for identification and interpretation of XPS data, 1995.

N. Katsonis, T. Kudernac, M. Walko, S. J. van der Molen, B. J. van Wees and B. L. Feringa, Adv. Mater., 2006, 18, 1397-1400. X. Zhang, T. Palamarciuc, P. Rosa, J. F. Létard, B. Doudin, Z. Zhang, J. Wang and P. A. Dowben, J. Phys. Chem. C, 2012, 116, 2329123296.

S. Tanaka, M. Toba, T. Nakashima, T. Kawai and K. Yoshino, Jpn. J. Appl. Phys., 2008, 47, 1215-1218.

J. Frisch, M. Herder, P. Herrmann, G. Heimel, S. Hecht and N. Koch, Appl. Phys. A, 2013, 113, 1-4.

G. A. Bain and J. F. Berry, J. Chem. Educ., 2008, 85, 532

J. J. Yeh and I. Lindau, At. Data Nucl. Data Tables, 1985, 32, 1-155. C. J. Mundy, F. Mohamed, F. Schiffman, G. Tabacchi, H. Forbert, W Kuo, J. Hutter, M. Krack, M. Iannuzzi, M. McGrath, M. Guidon, T. D. Kuehne, J. Vandevondele, V. Weber and T. Laino, .

A. D. Becke, Phys. Rev. A, 1988, 38, 3098-3100.

C. Lee, W. Yang and R. G. Parr, Phys. Rev. B, 1988, 37, 785-789. R. Sabatini, T. Gorni and S. de Gironcoli, Phys. Rev. B, 2013, 87, 41108.

J. VandeVondele and J. Hutter, J. Chem. Phys., 2007, 127, 114105.

Y. Zhang and W. Yang, Phys. Rev. Lett., 1998, 80, 890-890.

M. Reiher, Inorg. Chem., 2002, 41, 6928-6935. 